\title{
Liver Hepcidin and Stainable Iron Expression in Biliary Atresia
}

\author{
YING-HSIEN HUANG, HUI YU-HSIEH, CHAO-CHENG HUANG, VINCENT TSENG SHIN-MU, MING-HONG TAI, \\ CHAO-LONG CHEN, AND JIIN-HAUR CHUANG
}

\begin{abstract}
Department of Pediatrics [Y.-H.H.], Department of Pathology [C.-C.H.], Department of Surgery [C.L.C., J.-H.C.], Chang Gung Memorial Hospital at Kaohsiung, Kaohsiung, Taiwan 833, R.O.C.; Department of Computer Science and Information Engineering [H.Y-H., V.T.S.], National Cheng Kung University Tainan, Taiwan 701, R.O.C.; Department of Education and Research [M.H.T.], Veterans General Hospital, Kaohsiung, Taiwan 813, R.O.C.; Graduate Institute of Clinical Medical Sciences [Y.-H.H., C.-C.H., J.-H.C.], Chang Gung University, Lin-Ko, Taiwan 333, R.O.C.
\end{abstract}

\begin{abstract}
Hepcidin is a proposed mammalian host defense peptide that was identified on the basis of its antimicrobial activity, but it was later shown to be a crucial regulator of iron homeostasis and a mediator of the anemia of chronic inflammation. Hepcidin and stainable iron expression in biliary atresia (BA) were investigated in this study. Fresh liver tissues were obtained from 10 patients in the early stage of BA when they underwent Kasai's procedure, 9 in the late stage of BA when they received liver transplantation and 5 controls receiving liver resection for benign lesions other than cholestasis or fibrosis. Real-time quantitative reverse-transcription PCR (QRT-PCR), immunohistochemical staining and ELISA were performed to gauge hepcidin mRNA and protein expression in liver and plasma. Archival liver specimens from patients in the early and late stages of BA were treated with Perls' acid ferrocyanide technique for hepatic stainable iron. The results demonstrated that liver hepcidin mRNA expression was 100-fold lower in late-stage BA than in the early stage by QRT-PCR. Significantly weaker liver hepcidin immunostaining and lower plasma hepcidin levels were found in late-stage BA than in the early stage. There was also significantly lower stainable iron in the liver of late-stage BA. The major site of stainable iron was in Kupffer cells. The results support a role for hepcidin as a key regulator of mammalian iron metabolism and chronic inflammation, whose expression correlates with the degree of stainable iron in BA. (Pediatr Res 59: 662-666, 2006)
\end{abstract}

$\mathrm{B}^{\wedge}$ A is characterized by progressive destruction and obliteration of the extrahepatic bile ducts within months of birth. The exact etiology and pathogenesis of BA are still unknown. An infectious pathogen, in particular a virus, has long been suggested as the causative agent. Although some have been identified in limited number of patients with BA, none are universally isolated or identified in every case (1-4). In addition, genetic factors have been suggested as the pathogenesis, which is supported by the presence of congenital nonhepatic malformations, including cardiovascular defects, abdominal situs inversus, and sibling occurrence of BA and

Received July 19, 2005; accepted January 3, 2006.

Correspondence: Jiin-Haur Chuang, M.D., Ph.D., Chang Gung Memorial Hospital at Kaohsiung, Department of Surgery, 123 Ta-Pei Road, Niao-Sung Shiang, Kaohsiung, Taiwan 833, R.O.C.; e-mail: jhchuang@adm.cgmh.org.tw

Supported by grants from the Chang Gung Memorial Hospital (\#CMRPG8053) and the National Science Council (\#94-2314-B-182-036).

The online version of this article contains supplemental material at Pediatric Research online (www.pedresearch.org).

DOI: $10.1203 / 01 . p d r .0000214974 .55049 . f 1$ other congenital biliary disorders (5-8). From the study of the infectious animal model of BA, there are gaps in our understanding of the immunologic changes that are associated with BA. KP does not correct BA but is a palliative treatment (9). Despite early diagnosis and promptly performed KP to correct $\mathrm{BA}$, more than half of the patients still end up with liver cirrhosis. Because of the poor prognosis with KP alone, BA has been one of the major disorders necessitating liver transplantation in many transplant centers around the world, including in Taiwan $(10,11)$.

Because the causes and pathogenesis of BA might be multifactorial and dynamic, we undertook a large-scale geneexpression analysis by using the Human Genome U133A chips (Affymetrix, Santa Clara, CA) with 18,462 unique gene/ EST transcripts DNA microarray to study the genes up- or down-regulated during the progression of BA to liver cirrhosis. Hepcidin was very unique in that it showed a remarkable decrease in expression in the late stage of BA compared with the early stage. Human hepcidin was first isolated and characterized as a highly disulfide-bonded peptide with antimicrobial activity and was also named liver-expressed antimicrobial peptide-1, or LEAP-1 (12). Moreover, hepcidin, a gene that is up-regulated in the liver by inflammation and iron overload is a negative regulator of iron absorption from the duodenum and is released from macrophages (13-16). Because significant stainable iron was found in BA compared with idiopathic neonatal hepatitis (17), we hypothesized that hepcidin is a novel peptide involved in stainable iron expression and the progression of BA.

\section{METHODS}

Patients and samples. Fresh liver tissues were obtained from four male and six female patients in the early stages of BA when they received KP, and three male and six female patients at the late stages of BA when they received liver transplantation. Five control liver samples were from two male and three female patients undergoing liver resection for benign lesions of various

Abbreviations: BA, biliary atresia; HBV, hepatitis B virus; KP, Kasai's procedure; QRT-PCR, quantitative reverse-transcription PCR 
causes, including repairs of hiatus hernia and diaphragmatic hernia, corrections of malrotation and esophageal atresia, closure of gastrostomy, and partial hepatectomy for internal bleeding in which the livers were devoid of fibrosis and cholestasis. The mean ages of the patients in the early stage of $\mathrm{BA}$, late stage of BA, and control groups were $2.1 \pm 0.6,18.1 \pm 8.9$, and $30.5 \pm 28.5 \mathrm{mo}$, respectively. Detailed histories of the patients were recorded, including age when the patient received KP, sex, and blood transfusions (Table 1). Six liver explants from a male adult patient with decompensated $\mathrm{HBV}$-associated cirrhosis at the time of liver transplantation and six noncirrhotic normal liver specimens from four male and two female patients receiving liver resection for $\mathrm{HBV}$-associated hepatoma were used as disease controls. The mean ages of these HBV-cirrhotic and -noncirrhotic patients were $43.6 \pm 4.3$ and $47.3 \pm 15.7 \mathrm{y}$, respectively. After surgical removal, all the samples were immediately divided into several pieces, put into cryogenic vials (Corning, Corning, NY), immersed in liquid nitrogen, and then stored at $-80^{\circ} \mathrm{C}$ until use. The study was executed with the approval of the Ethics and Clinical Research Committee of the Chang Gung University, and informed consent was obtained from the parents.

Microarray data analysis. For DNA microarray, three liver samples from the patients in the early stage of BA and three from the late stage were analyzed by using the Human Genome U133A chips (Affymetrix) with 18,462 unique gene/EST transcripts DNA microarray. We strictly followed the protocol provided by the manufacturer. Only those genes with present call by Affymetrix criteria were selected for further analysis. To obtain the most informative genes, a threshold number of misclassification (TNoM), originally described by Ben-Dor et al. (18) and adopted by Zuo et al. (19), was used in this study. TNoM counted the number of classification errors committed when using the best simple threshold to distinguish two classes (early stage or late stage of BA) based on the expression levels of a specific gene. We proceeded further to use Info to estimate the residual uncertainty about the sample classification (early stage or late stage of BA) after incorporating predictions based on expression of an individual gene. A low Info score indicated a high predictive value for a given gene. Finally, Gaussian was used to narrow down the number of genes that best distinguished early from late stage BA. Gaussian was the estimate of overlap between the distribution of expression levels for a gene in two classes, and the score was based on normality assumption. Different levels of Info and Gausssian were used to obtain the most useful genes for distinguishing early from late stage BA in the liver. Finally, we could obtain an informative ranked gene list (see supplemental material online) and verify them by QRT-PCR

$R N A$ isolation and real-time $Q R T-P C R$. To quantitate the tissue amount of hepcidin mRNA, we used real-time QRT-PCR with the ABI $7700 \mathrm{Se}-$ quence Detection System (TaqMan, Applied Biosystems, Foster City, CA). The rationale for using this equipment is that real-time RT-PCR is a sensitive and reliable method for RNA quantitation (20). Total RNA was extracted from the liver tissue. For real-time QRT-PCR, the reagent mixture was prepared according to the protocol provided by the manufacturer (Protech Technology, Taipei, Taiwan). Two micrograms of total RNA was used to generate cDNA using an oligodeoxynucleotide primer (oligo dT15) following the protocol for transcription (Promega, Madison, WI). PCR was performed in $50 \mu \mathrm{L}$ SYBR Green PCR Master Mix (Applied Biosystems) containing 10 $\mu \mathrm{M}$ forward primers and reverse primers, and approximately $30 \mathrm{ng}$ cDNA. The primers sequences for the hepcidin and the $\beta$-actin were $5^{\prime}$ TCCCACAACAGA CGGGACA- $3^{\prime}$ and $3^{\prime}$-GTCGACCTACGGGTACAAG-5' and $5^{\prime}$-TCACCCACACTGTGCCCATCTACGA-3' and $3^{\prime}$ GGTAACCGTTACTCGCCAAGGCGAC-5', respectively. Amplification and detection were performed with the ABI 7700 System with the following profile: 1 cycle of $95^{\circ} \mathrm{C}$ for $10 \mathrm{~min}, 40$ cycles of $95^{\circ} \mathrm{C}$ for $15 \mathrm{~s}, 60^{\circ} \mathrm{C}$ for $30 \mathrm{~s}$, and $72^{\circ} \mathrm{C}$ for $15 \mathrm{~s}$. After amplification was complete, a final melting curve was performed with 2 min of denaturation at $95^{\circ} \mathrm{C}$, then cooling to $60^{\circ} \mathrm{C}$ and heating slowly until $95^{\circ} \mathrm{C}(20 \mathrm{~min})$ according to the dissociation protocol of the ABI 7700 instrument. Real-time fluorescence measurement was read and

Table 1. Demographic and clinical data for 24 children in QRT-PCR study

\begin{tabular}{lccc}
\hline \multicolumn{1}{c}{ Clinical feature } & $\begin{array}{c}\text { Early stage of BA } \\
(n=10)\end{array}$ & $\begin{array}{c}\text { Late stage of BA } \\
(n=9)\end{array}$ & $\begin{array}{c}\text { Control } \\
(n=5)\end{array}$ \\
\hline Age $(\mathrm{mo})$ & $2.1 \pm 0.6$ & $18.1 \pm 8.9$ & $30.5 \pm 28.5$ \\
Gender $($ male:female $)$ & $4: 6$ & $3: 6$ & $2: 3$ \\
Transfusion $(n)^{*}$ & 0 & 6 & 0 \\
Ferritin $(\mu \mathrm{g} / \mathrm{L}) \dagger$ & $2941 \pm 3260$ & $115 \pm 74$ & - \\
\hline
\end{tabular}

$* n=$ Number of patients ever receiving blood transfusion.

$\dagger$ There were five samples each for early and late stages of BA but none for the controls. a threshold cycle $\left(\mathrm{C}_{\mathrm{T}}\right)$ value for each sample was calculated by determining the point at which the fluorescence exceeded a threshold limit, i.e., 10 times above the $\mathrm{SD}$ of the baseline. The $\mathrm{C}_{\mathrm{T}}$ value from the samples was plotted on the standard curve, and the copy number was calculated automatically by Sequence Detection Version 1.6 (Applied Biosystems). Each sample was tested in duplicate and the mean of the two values was chosen as copy number of the sample. Samples were defined as negative if the $C_{T}$ values exceeded 50 cycles. Primers and probes for the target genes were chosen with the assistance of computer program Primer Express (Applied Biosciences). The mRNA of the $\beta$-actin was chosen as internal control in each sample to control sample-to-sample variations in RNA concentration. Relative quantification of gene expression was based on the comparative $\mathrm{C}_{\mathrm{T}}$ method, in which the amount of target was given by $2-^{(\Delta \mathrm{CT} \text { target }-\Delta \mathrm{CT} \text { calibrator })}$ or $2{ }^{\Delta \Delta \mathrm{CT}}$. The calibrator was chosen as it had the lowest expression value across the groups for the same gene under statistical comparison. PCR products were electrophoresed on a $1.5 \%$ agarose gel to confirm the sizes of the products. To validate the transcripts obtained by QRT-PCR, cDNA from three random liver samples was used for serial dilution $(1: 2,1: 4,1: 16$, and 1:32) to obtain a relative standard curve, which revealed a perfect correlation throughout the dilutions $\left(R^{2}=0.99\right)$. The validation experiments were done in triplicate and amplification efficiencies were validated (21).

Immunohistochemistry. Immunohistochemical staining of hepcidin was performed on paraffin-embedded, formalin-fixed, archival liver tissues obtained from the Department of Pathology, Chang Gung University. Twomicrometer sections were deparaffinized, treated with 3\% hydrogen peroxide to inactivate the endogenous peroxidase activity, and microwaved for $10 \mathrm{~min}$ in $10 \mathrm{mM}$ citrate buffer to retrieve antigen. After incubating the sections in $2 \%$ normal horse serum (Vector Laboratories, Burlingame, CA) for $10 \mathrm{~min}$ to block the background, the sections were incubated with rabbit anti-hepcidin antibody (Alpha Diagnostic International, San Antonio, TX; Cat. \# HEPC 12-A, 1:200 dilution) at $4^{\circ} \mathrm{C}$ overnight. The sections were then washed with PBS and incubated with HRP-rabbit anti-goat-IgG (DAKO, Copenhagen, Denmark) according to the manufacturer's instructions and then with DAB chromogen. Because hepcidin is expressed in normal liver, a liver sample from a 4.5-mo-old infant served as normal, positive control $(12,16)$. Omitting the primary antibody in one of the samples from a patient in the early stage of BA served as negative control. The intensity of immunoreactivity for hepcidin was graded according to the following criteria: grade 0 , no visible immunoreactive dot; grade 1 , immunoreactive dots visible less than positive control; grade 2, immunoreactive dots visible equal to positive control; and grade 3 , immunoreactive dots visible more than positive control.

Perls' acid ferrocyanide stain. Liver tissues were obtained from 18 patients in the early stage of BA and 16 in the late stage. Paraffin-embedded, formalin-fixed sections were deparaffinized and hydrated with distilled water. We then mixed equal parts of hydrochloric acid and potassium ferrocyanide prepared immediately before use. Slides were immersed in this solution for 20 min and washed in distilled water for three changes. The slides were counterstained with nuclear fast red for $5 \mathrm{~min}$, rinsed twice in distilled water, and then dehydrated through $95 \%$ and two changes of 100\% alcohol. The slides were cleared in xylene, two changes, for 3 min each and then covered with resinous mounting medium. In this stain, iron (ferric form) was bright blue, nuclei were stained red, and cytoplasm was pink. Grading of iron staining in the liver was divided into two parts according to the presence of stainable iron in either hepatocytes or Kupffer cells (22). Hepatocyte iron staining was graded as 0 , indicating no visible iron; grade 1 , iron visible in very few hepatocytes; grade 2 , iron visible in $5-10 \%$ of hepatocytes; grade 3 , iron visible in $>40 \%$ of hepatocytes; and grade 4 , abundant iron visible in most hepatocytes. Kupffer cell iron staining was graded as 0 , no visible iron in Kupffer cells; grade 1, iron visible in one-third of Kupffer cells; grade 2, iron visible in one-third to two-thirds of Kupffer ells; and grade 3, abundant iron visible in more than two-thirds of Kupffer cells. Hepatocyte or Kupffer cell iron of grade 0 or 1 was defined as normal. Increased stainable iron was defined as hepatocyte and/or Kupffer cell iron grade $\geq 2$ (22).

Hepcidin ELISA competitive binding assay. Plasma samples were obtained from five healthy individuals without liver diseases (three males, two females, aged $40 \pm 31.7 \mathrm{mo}$ ), eight patients in the early stage of BA (four males, four females, aged $1.8 \pm 0.3 \mathrm{mo}$ ), seven patients in the late stage of BA (three males, four females, aged $12 \pm 4.5 \mathrm{mo}$ ), and five patients (three males, two females, aged $43 \pm 41.7 \mathrm{mo}$ ) with jaundice-free course after successful KP who received regular follow-up in our hospital. Determinations were performed by using 96 -well microtitre plates coated with a polyclonal rabbit antibody against hepcidin-(28-47) designed by Kulasksiz et al. (23) and the antibody conjugate with biotin molecule compete for the binding sites of the pro-hepcidin antibodies immobilized on the wells (EIA-4015, LOT 12K055, Hepcidin Prohormone ELISA; DRG Instruments GmbH, Marburg, Germany). Assay procedures were according to the manufacturer's instructions and the absorbance of each well was determined at $450 \mathrm{~nm}$ wavelength. 
Statistical analysis. Linear regression was used to determine the correlation in two parametric data. One-way ANOVA was used to determine differences in parametric data between groups. The degree of stainable iron in early and late-stage BA was compared by the Spearman's rank correlation coefficient. A $p$ value $<0.05$ was regarded as statistically significant.

\section{RESULTS}

Hepcidin mRNA expression. Hepcidin was one of 200 genes that showed a more than 2-fold decrease in expression in the late stage of BA compared with the (see supplemental material online) early stage. By using QRT-PCR analysis, we found that liver mean hepcidin mRNA expression was more than 100-fold less in late stage BA than in early stage $(p<$ 0.001). Although liver hepcidin mRNA expression was higher in the early stage of BA than in controls, the difference was not statistically significant. An analysis was done to correlate age with liver hepcidin mRNA levels, and no significant correlation was found between age and liver hepcidin mRNA levels, no matter whether all the BA patients and the controls were pooled together $\left(R^{2}=0.038, p=0.364\right)$ or if the data were split into the early stage of BA $\left(R^{2}=0.096, p=0.148\right)$, the late stage of $\mathrm{BA}\left(R^{2}=0.07, p=0.819\right)$, and the control group $\left(R^{2}=0.011, p=0.864\right)$, respectively. Additionally, in our unpublished observations, liver hepcidin mRNA levels in normal adults were not significantly different from those in healthy children. There was also no significant difference in liver hepcidin mRNA expression between cirrhotic and noncirrhotic stages of HBV-associated liver diseases $(p=0.749)$ (Fig. 1).

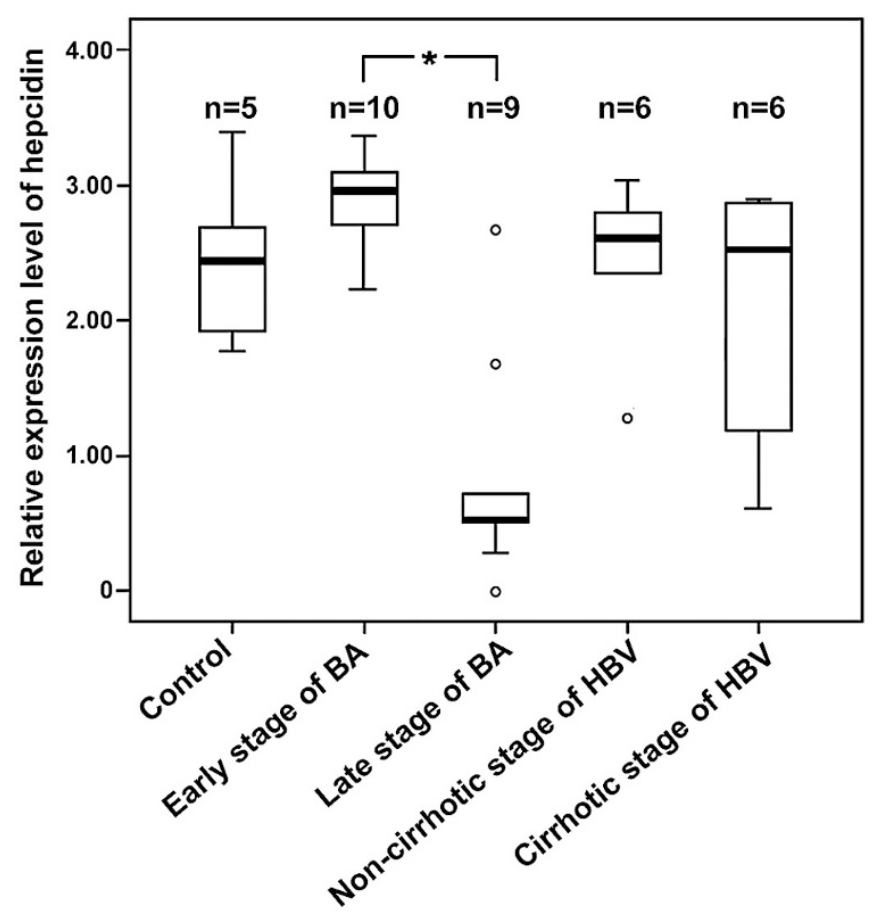

Figure 1. Comparison of hepcidin mRNA expression by real-time QRT-PCR between early and late-stage BA as well as between cirrhotic and noncirrhotic stages of HBV. Logarithmic transformation of fold changes between stages was performed, as there was a more than 100 -fold difference between groups. *Significant difference between groups. The thick line within the box indicates the median. The lower and upper edges of the box indicate the first and third quartiles and the whiskers the minimum and maximum values. The circles indicate the outliers.
Immunoreactive hepcidin staining. There was significantly higher signal intensity in immunoreactive hepcidin staining in the early stage of BA than in the late stage (Fig. 2, $A$ and $B$ ). The trend of hepcidin protein expression was the same as hepcidin mRNA expression. Control liver showed weak (grade 1) to moderate (grade 2) staining, with some parable to that in the early stage of BA. Furthermore, hepcidin was seen in both the cytoplasm and the nucleus of hepatocytes.

Perls' iron staining. Hepatic stainable iron decreased significantly in the late stage of BA when compared with the early stage (Table 2; Fig. 2, $D$ and $E$ ). Eleven of 18 and 8 of 18 archival liver specimens from early stage BA had stronger stainable iron in Kupffer cells and hepatocytes, respectively. There were also more coarse granules of stainable iron in Kupffer cells than in hepatocytes. This phenomenon of siderosis correlated well with early stage and late-stage BA (Spearman's $\sigma=0.814, p<0.001$ ).

Plasma ferritin was higher in the early stage of BA than in the late stage. The difference was significant after logarithmic transformation of the data $(p=0.001)$ because of extreme variation of ferritin levels in early stage of BA (Table 1).

Plasma hepcidin levels in BA and normal controls. The levels of plasma hepcidin were highest in the early stage of BA, followed by normal controls, and lowest in the late stage of BA. The difference reached significance when comparing plasma hepcidin in late-stage BA with early stage $(p=0.02)$. Although plasma hepcidin levels were higher in jaundice-free BA patients after KP than in those who failed KP and required liver transplantation, the difference was not significant (Fig. 3). The plasma hepcidin also showed the same trend as liver hepcidin mRNA expression

\section{DISCUSSION}

Our results demonstrated that hepcidin mRNA expression by QRT-PCR analysis decreased significantly in the late stage of BA, which is consistent with our oligonucleotide microarray study. Because we could not obtain liver tissue from the BA patients who were well after KP and regularly followed at outpatient service, we checked the plasma hepcidin levels using ELISA instead. The trend of hepcidin protein expression by immunohistochemical staining of liver hepcidin or by ELISA assay of plasma hepcidin levels was the same as the liver hepcidin mRNA expression. Interestingly, plasma hepcidin levels were higher in jaundice-free BA patients after KP than in those who failed KP and needed liver transplantation. It is possible that the change of hepcidin expression in BA may reflect the progression of liver fibrosis. In the study of Aoki et al. (24), however, the level of liver hepcidin expression was not related to the degree of fibrosis in hepatitis $\mathrm{C}$ virus infection, and there was no decrease of hepcidin as liver function deteriorated. In our results, there was also no downregulation of hepcidin mRNA expression in HBV-related cirrhosis compared with noncirrhotic HBV controls. It is likely that the decreased hepcidin expression in the late stage of BA may either reflect cholestatic liver injury characteristic of BA or be a disease-specific phenomenon.

Hepcidin is a proposed mammalian host defense peptide that was identified as such on the basis of its antimicrobial 


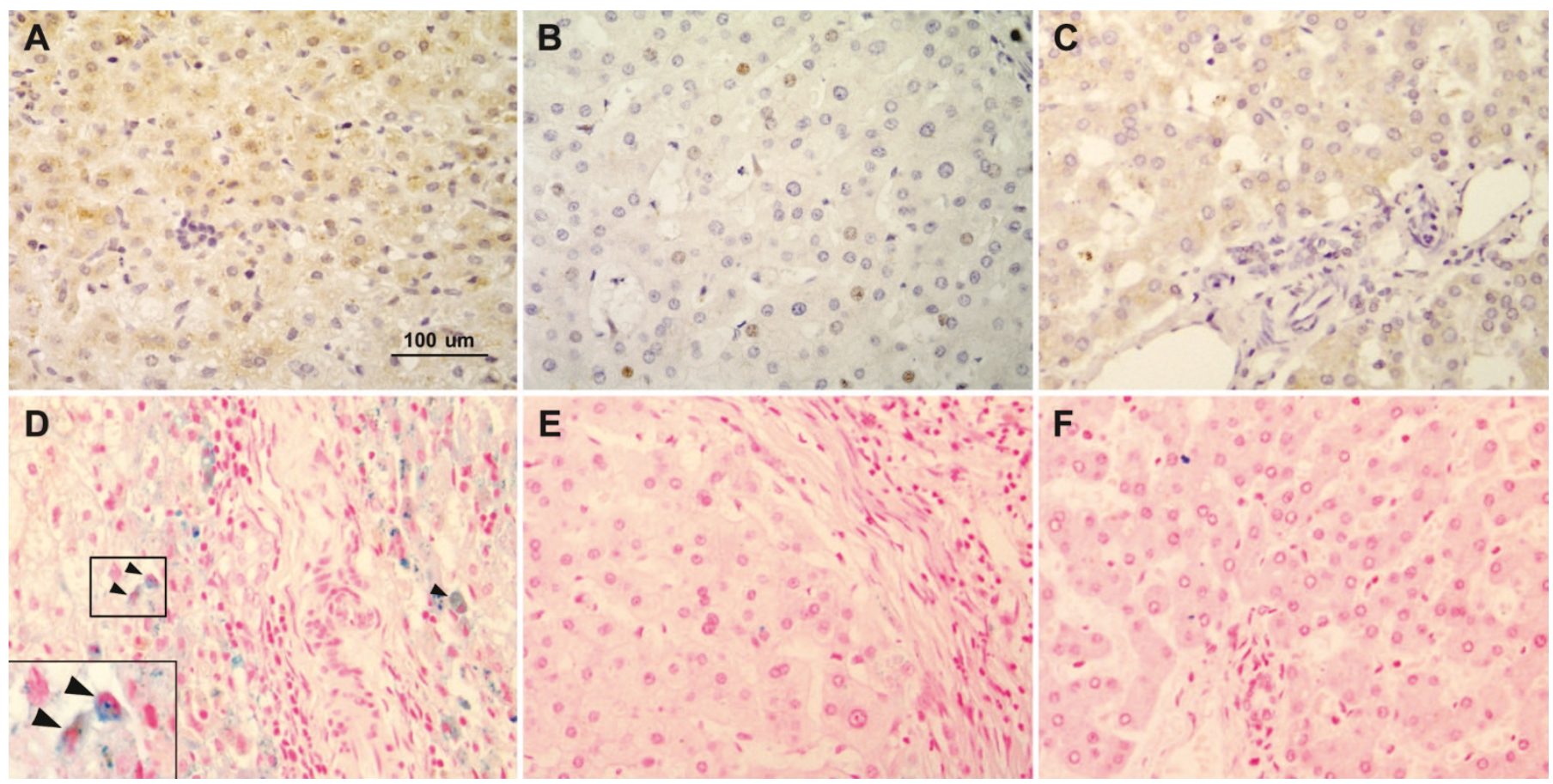

Figure 2. Immunoreactive hepcidin staining of representative liver tissues (brown color) shows a grade-3 staining in the early stage of BA (A), a weak grade-1 staining in the late stage $(B)$, and a grade-2 staining in a 4.5-mo-old child without liver disorder serving as a positive control $(C)$. Hepcidin was localized in the cytoplasm and the nucleus of the hepatocytes. Perls' stain showed remarkably higher stainable iron (blue color) in early stage of BA ( $D$ ), with grade 2 in Kupffer cells and 3 in hepatocytes, than in late stage of BA $(E)$, with grade 0 in Kupffer cells and 1 in hepatocytes. Stainable iron localized mainly in Kupffer cells (arrowheads). A 3.1-mo-old infant with grade-0 iron staining in Kupffer cells and 1 in hepatocytes was used as control $(F)$. The insert shows the amplification of Kupffer cells. (Original magnification, $\times 400$; insert, $\times 800$ )

Table 2. Comparison of stainable iron between the early and the late stage of $B A$

\begin{tabular}{|c|c|c|c|c|c|}
\hline \multirow[b]{2}{*}{ Disease status and sites } & \multicolumn{5}{|c|}{ Grade $(\%)$} \\
\hline & 0 & 1 & 2 & 3 & 4 \\
\hline \multicolumn{6}{|l|}{$\begin{array}{l}\text { Early stage of BA } \\
\quad(n=18)\end{array}$} \\
\hline Kupffer cell & $1(5.6)$ & $6(33.3)$ & $6(33.3)$ & $5(27.8)$ & $\mathrm{NA}^{*}$ \\
\hline Hepatocyte & $1(5.6)$ & $9(50)$ & $5(27.8)$ & $3(16.7)$ & 0 \\
\hline \multicolumn{6}{|l|}{$\begin{array}{l}\text { Late stage of BA } \\
\qquad(n=16)\end{array}$} \\
\hline Kupffer cell $\dagger$ & $16(100)$ & 0 & 0 & 0 & NA \\
\hline Hepatocyte & $13(81.3)$ & $3(18.7)$ & 0 & 0 & 0 \\
\hline
\end{tabular}

*The present grading system does not include Kupffer cell iron staining greater than 3 .

$\dagger p<0.001$, comparing stainable iron in Kupffer cells or hepatocytes between the early and the late stage of BA.

activity, but it has lately been shown to be a crucial regulator of iron homeostasis and a mediator of the anemia of inflammation (13-16). The antimicrobial activity of hepcidin occurs only at supraphysiologic concentrations and is therefore of doubtful significance in clinical practice. However, the antimicrobial property for Escherichia coli in hepcidin is meaningful, as $E$. coli is the most common bacterium involved in postoperative cholangitis in BA $(25,26)$. Postoperative cholangitis is the most common complication following KP for BA, which exacerbates preexisting liver fibrosis (27), leading to end-stage liver cirrhosis necessitating liver transplant in the late stage of BA. Patients who receive liver transplantation for

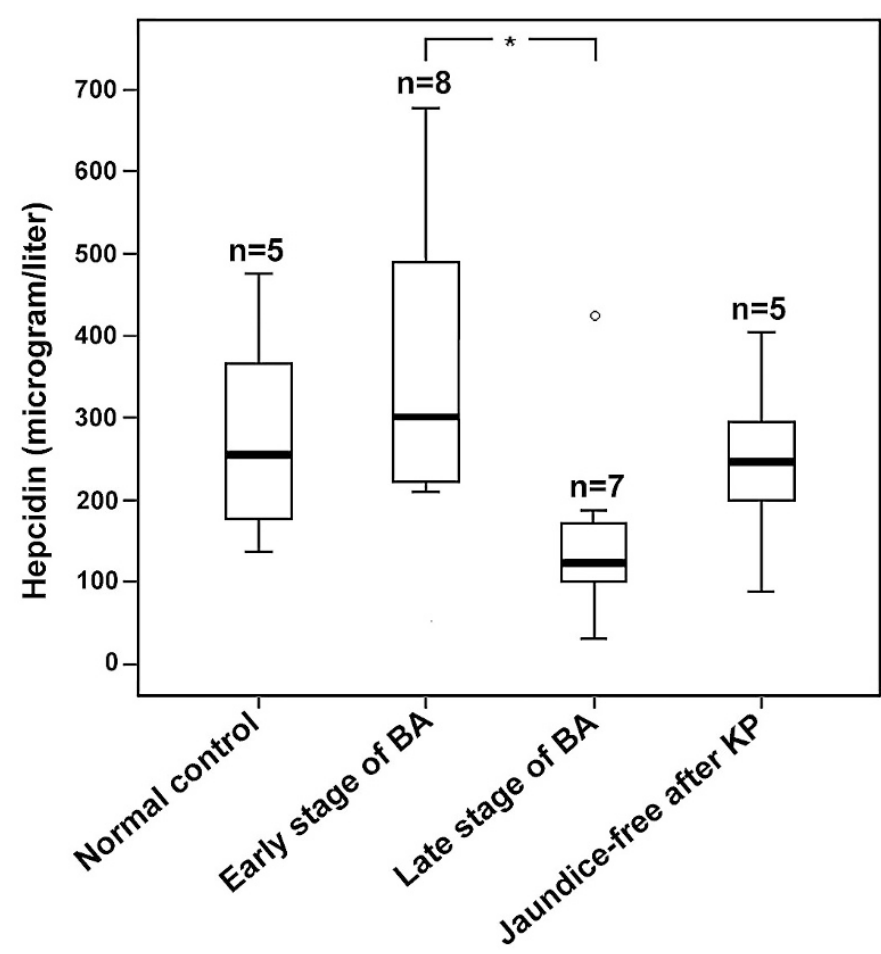

Figure 3. Plasma hepcidin levels were measured by ELISA assay in early and late stages of BA and in normal controls, as well as in jaundice-free patients of BA after KP and in patients who failed KP and needed liver transplantation. *Significant difference between groups. The thick line within the box indicates the median. The lower and upper edges of the box indicate the first and third quartiles and the whiskers the minimum and maximum values. The circle indicates the outlier. 
salvage experience more episodes of infection in the hepatobiliary system than those who survive with their native liver (28). Theoretically, hepcidin should be up-regulated in the late stage of BA as a consequence of chronic infection and inflammation. The fact that hepcidin is significantly lower in the late stage of BA than in the early stage implies that there may exist an inherent defect in hepcidin production in some patients with BA who are prone to develop postoperative cholangitis and consequently liver cirrhosis. Or, alternatively, like other proteins produced by the hepatocytes, hepcidin is produced in reduced amounts in the end-stage liver cirrhosis. The latter is less likely because of no down-regulation of hepcidin mRNA expression in hepatitis B or C virus-related cirrhosis.

Hepatic stainable iron was significantly increased in the early stage of BA in this study, which was consistent with the observation of Tazawa et al. (17) of increased siderosis in BA. The results of autopsied young patients without liver disorder revealed that stainable iron was present in the liver in only two out of nine, indicating that liver deposition is an infrequent event in normal children. Even in infants $<2$ mo of age, positive iron stain was present in 7 out of 22 newborn liver tissues (29). Decreased stainable iron in the late stage of BA may be a consequence of decreased hepcidin expression or vice versa. The serum ferritin level is raised as the result of increased storage of tissue iron and severe hepatocellular injury in newborn infants, irrespective of the cause (30). Blood transfusion may increase serum ferritin level and stainable iron in the liver (31). However, in this study, the ferritin level in late stage of BA after one to several episodes of blood transfusion was still far less than that in the early stage, indicating the plasma ferritin level and the liver stainable iron expression were affected more by the disease entity than by blood transfusion.

Our finding of nuclear localization of hepcidin or prohepcidin in hepatocytes is novel but is not exceptional. In a study of iron overloading in a murine model, the overexpressed green fluorescent protein-prohepcidin protein was exclusively localized in the nucleus (16). When the putative nuclear localization signal was deleted, the resulting protein was addressed to the cytoplasm. The researchers assumed that the prohepcidin could be transitorily addressed to the nucleus before relocation to the cytoplasm and secretion. But in a study of cellular localization of hepcidin in the liver in patients with hereditary hemochromatosis, chronic renal insufficiency, and renal anemia, hepcidin immunoreactivity was confined to the basolateral (sinusoidal) membrane domain of hepatocytes, and there was no mention of hepcidin localization in the nucleus (23). It is reasonable to assume that the subcellular localization of hepcidin in human liver may vary according to the underlying diseases.

Acknowledgments. The authors thank Ms. Chia-Ling Wu for her excellent technical support and the liver transplant team of this hospital, led by professor Chao-Long Chen, for assistance in recruiting patients in this study.

\section{REFERENCES}

1. Fischler B, Ehrnst A, Forsgren M, Orvell C, Nemeth A 1998 The viral association of neonatal cholestasis in Sweden: a possible link between cytomegalovirus infection and extrahepatic biliary atresia. J Pediatr Gastroenterol Nutr 27:57-64

2. Drut R, Drut RM, Gomez MA, Cueto Rua E, Lojo MM 1998 Presence of human papillomavirus in extrahepatic biliary atresia. J Pediatr Gastroenterol Nutr 27:530-535

3. Bobo L, Ojeh C, Chiu D, Machado A, Colombani P, Schwarz K 1997 Lack of evidence for rotavirus by polymerase chain reaction/enzyme immunoassay of hepatobiliary samples from children with biliary atresia. Pediatr Res 41:229-234

4. Mason AL, Xu L, Guo L, Munoz S, Jaspan JB, Bryer-Ash M, Cao Y, Sander DM, Shoenfeld Y, Ahmed A, Van de Water J, Gershwin ME, Garry RF 1998 Detection of retroviral antibodies in primary biliary cirrhosis and other idiopathic biliary disorders. Lancet 351:1620-1624

5. Redkar R, Davenport M, Howard ER 1998 Antenatal diagnosis of congenital anomalies of the biliary tract. J Pediatr Surg 33:700-704

6. Tanano H, Hasegawa T, Kawahara H, Sasaki T, Okada A 1999 Biliary atresia associated with congenital structural anomalies. J Pediatr Surg 34:1687-1690

7. Carmi R, Magee CA, Neill CA, Karrer FM 1993 Extrahepatic biliary atresia and associated anomalies: etiologic heterogeneity suggested by distinctive patterns of associations. Am J Med Genet 45:683-693

8. Ando K, Miyano T, Fujimoto T, Ohya T, Lane G, Tawa T, Tokita A, Yabuta K 1996 Sibling occurrence of biliary atresia and biliary dilatation. J Pediatr Surg 31:1302-1304

9. Czech-Schmidt G, Verhagen W, Szavay P, Leonhardt J, Petersen C 2001 Immunological gap in the infectious animal model for biliary atresia. J Surg Res 101:62-67

10. Chen CL, Chen YS, de Villa VH, Wang CC, Lin CL, Goto S, Wang SH, Cheng YF, Huang TL, Jawan B, Cheung HK 2000 Minimal blood loss living donor hepatectomy. Transplantation 69:2580-2586

11. Jain A, Reyes J, Kashyap R, Dodson SF, Demetris AJ, Ruppert K, Abu-Elmagd K, Marsh W, Madariaga J, Mazariegos G, Geller D, Bonham CA, Gayowski T, Cacciarelli T, Fontes P, Starzl TE, Fung JJ 2000 Long-term survival after liver transplantation in 4,000 consecutive patients at a single center. Ann Surg 232:490-500

12. Krause A, Neitz S, Magert HJ, Schulz A, Forssmann WG, Schulz-Knappe P, Adermann K 2000 LEAP-1, a novel highly disulfide-bonded human peptide, exhibits antimicrobial activity. FEBS Lett 480:147-150

13. Andrews NC 2004 Anemia of inflammation: the cytokine-hepcidin link. J Clin Invest 113:1251-1253

14. Ganz T 2003 Hepcidin, a key regulator of iron metabolism and mediator of anemia of inflammation. Blood 102:783-788

15. Nemeth E, Rivera S, Gabayan V, Keller C, Taudorf S, Pedersen BK, Ganz T 2004 IL-6 mediates hypoferremia of inflammation by inducing the synthesis of the iron regulatory hormone hepcidin. J Clin Invest 113:1271-1276

16. Pigeon C, Ilyin G, Courselaud B, Leroyer P, Turlin B, Brissot P, Loreal O 2001 A new mouse liver-specific gene, encoding a protein homologous to human antimicrobial peptide hepcidin, is overexpressed during iron overload. J Biol Chem 276:7811-7819

17. Tazawa Y, Abukawa D, Maisawa S, Nishinomiya F, Oyake Y, Takada G, Konno T 1998 Idiopathic neonatal hepatitis presenting as neonatal hepatic siderosis and steatosis. Dig Dis Sci 43:392-396

18. Ben-Dor A, Bruhn L, Friedman N, Nachman I, Schummer M, Yakhini Z 2000 Tissue classification with gene expression profiles. J Comput Biol 7:559-583

19. Zuo F, Kaminski N, Eugui E, Allard J, Yakhini Z, Ben-Dor A, Lollini L, Morris D, Kim Y, DeLustro B, Sheppard D, Pardo A, Selman M, Heller RA 2002 Gene expression analysis reveals matrilysin as a key regulator of pulmonary fibrosis in mice and humans. Proc Natl Acad Sci USA 99:6292-6297

20. Gibson UE, Heid CA, Williams PM 1996 A novel method for real time quantitative RT-PCR. Genome Res 6:995-1001

21. Li AC, Brown KK, Silvestre MJ, Willson TM, Palinski W, Glass CK 2000 Peroxisome proliferator-activated receptor gamma ligands inhibit development of atherosclerosis in LDL receptor-deficient mice. J Clin Invest 106:523-531

22. Barton JC, Edwards CQ, Bertoli LF, Shroyer TW, Hudson SL 1995 Iron overload in African Americans. Am J Med 99:616-623

23. Kulaksiz H, Gehrke SG, Janetzko A, Rost D, Bruckner T, Kallinowski B, Stremmel W 2004 Pro-hepcidin: expression and cell specific localisation in the liver and its regulation in hereditary haemochromatosis, chronic renal insufficiency, and renal anaemia Gut 53:735-743

24. Aoki CA, Rossaro L, Ramsamooj R, Brandhagen D, Burritt MF, Bowlus CL 2005 Liver hepcidin mRNA correlates with iron stores, but not inflammation, in patients with chronic hepatitis C. J Clin Gastroenterol 39:71-74

25. Park CH, Valore EV, Waring AJ, Ganz T 2001 Hepcidin, a urinary antimicrobial peptide synthesized in the liver. J Biol Chem 276:7806-7810

26. Wu ET, Chen HL, Ni YH, Lee PI, Hsu HY, Lai HS, Chang MH 2001 Bacterial cholangitis in patients with biliary atresia: impact on short-term outcome. Pediatr Surg Int 17:390-395

27. Lunzmann K, Schweizer P 1999 The influence of cholangitis on the prognosis of extrahepatic biliary atresia. Eur J Pediatr Surg 9:19-23

28. Jiang CB, Lee HC, Yeung CY, Sheu JC, Chang PY, Wang NL, Yeh CY 2003 A scoring system to predict the need for liver transplantation for biliary atresia after Kasai portoenterostomy. Eur J Pediatr 162:603-606

29. Faa G, Sciot R, Farci AM, Callea F, Ambu R, Congiu T, van Eyken P, Cappai G, Marras A, Costa V 1994 Iron concentration and distribution in the newborn liver. Liver 14:193-199

30. Knisely AS 1992 Neonatal hemochromatosis. Adv Pediatr 39:383-403

31. Ng PC, Lam CW, Lee CH, To KF, Fok TF, Chan IH, Wong E 2001 Hepatic iron storage in very low birthweight infants after multiple blood transfusions. Arch Dis Child Fetal Neonatal Ed 84:F101-F105 